\title{
CBS ve Frekans Oranı Yöntemi Kullanılarak Isparta-Burdur Dağ Yolu Heyelan Duyarlılığının Değerlendirilmesi
}

\author{
Kerem HEPDENIZ ${ }^{1}$, İ. İskender SOYASLAN ${ }^{2 *}$ \\ ${ }^{1}$ Mehmet Akif Ersoy Üniversitesi, Bucak Emin Gülmez Teknik Bilimleri MYO, Burdur \\ 2 Mehmet Akif Ersoy Üniversitesi Mühendislik Mimarlık Fakültesi, Burdur \\ Geliş Tarihi (Received): 11.04.2018, Kabul Tarihi (Accepted): 10.07.2018 \\ $\square$ Sorumlu Yazar (Corresponding author*): isoyaslan@mehmetakif.edu.tr \\ (C) +902482132717 圆 +902482132704
}

öz

Isparta - Burdur arasındaki mesafeyi 52 kilometreden 21 kilometreye indiren ve dağ yolu olarak da bilinen yolda, özellikle yağışı aylarda heyelanlar meydana gelmektedir. Çalışma alanı, yapım çalışmaları sonrasında trafiğe açılmış ve ağır vasıtalar da dahil olmak üzere, pek çok vasıta sürücüsünün tercih ettiği bir yol haline gelmiştir. Bölgenin sahip olduğu dağlık topografya, jeolojik ve jeomorfolojik özelliklerin yanı sıra iklim koşulları ve sismik potansiyel gibi etkenler bölgede heyelan oluşumlarına neden olduğu düşünülmektedir. Bu çalışmada, Isparta-Burdur illeri arasındaki dağ yolunun, Coğrafi Bilgi Sistemleri (CBS) tabanlı frekans oranı (FR) yöntemi kullanılarak, heyelan duyarlılık haritasının oluşturulması ve heyelanlara neden olan faktörlerin belirlenmesi amaçlanmıştır. Bu amaç doğrultusunda yapılan analizlerde; topografik yükseklik, jeoloji, yola yakınlık, eğim, bakı ve yamaç eğiminden oluşan altı parametre kullanılmıştır. Analizlerin daha hassas, hızlı olması ve kolaylık sağlaması açısından yöntem olarak CBS seçilmiştir. Büro çalışmaları ile oluşturulan altık veriler, saha çalışmalarının hızlanmasına ve daha doğru verilere ulaşıımasını sağlamıştır. Çalışma alanı içerisindeki heyelan alanları saha gözlemleri yapılarak 1/25000 ölçekli topografik haritalara işlenmiştir. Çalışma sonucunda elde edilen duyarlılık haritalarının; planlamacılar, karar vericiler ve yerel yönetimlerin karar mekanizmalarında altık olarak kullanılacağı düşünülmektedir.

Anahtar Kelimeler: CBS, Frekans oranı, Heyelan, Duyarlılık haritası, Isparta, Burdur

\section{Landslide Evaluation of Isparta-Burdur Mountain Road by Using GIS and Frequency Ratio Method}

\begin{abstract}
Landslides are coming to the road especially in rainy months on the road, which is known as mountain road, which brings the distance between Isparta and Burdur to $21 \mathrm{~km}$ from $52 \mathrm{~km}$. The work area has been trafficked after construction work and has become the preferred route for many vehicle drivers, including heavy vehicles. It is thought that factors such as mountainous topography, geological and geomorphological features, climatic conditions and seismic potential of the region cause landslide formation in the region. In this study, it was aimed to determine landslide susceptibility map and determine the factors causing landslides by using Geographical Information Systems (GIS) based frequency ratio (FR) method in the mountain road between Isparta and Burdur. In the analyzes made for this purpose; topography height, geology, proximity to the road, slope, elevation and slope inclination. GIS has been chosen as a method to make analysis more precise, faster and easier. The bases generated by the office
\end{abstract}


workings helped to accelerate fieldwork and achieve more accurate data. Landslide areas in the study area were field observations and 1/25000 scale topographic maps were processed. The sensitivity maps obtained at the end of the study; planners, decision makers and local governments.

Keywords: GIS, Landslide, Frequency ratio, Sensitivity map, Isparta, Burdur

\section{Giriş}

Ülkemizde nüfus ile birlikte artan araç sayısı, lojistik faaliyetler ve işgücü, ulaşım amaçlı yeni yolların yapılmasını gerekli kılmıştır. Bazı yol yapım uygulamalarında; bu yollar yapılırken, arazinin sahip olduğu ilk şekil bozulmakta ve arazide birtakım değişiklikler meydana gelebilmektedir. Bu değişiklikler ise arazide; heyelan, kaya düşmesi ve çığ gibi kitle hareketlerinin oluşumuna neden olabilmektedir.

Heyelan, kayaç, moloz ve toprak malzemeler ile bunların karışımının, yerçekiminin etkisi ile aşağı yönde hareketi olarak tanımlanır (Cruden ve Varnes, 1996). Heyelan duyarlılık haritalamaları, heyelan riskini ve zararlarını azaltma çalışmaları için önemli bir altık niteliğindedir.

Heyelan duyarlılığı, bölgenin şev kayması üretme potansiyeli olarak tanımlanır ve yatkınlık genellikle plan, harita, kesit ve üçboyutlu modellerler ifade edilir (Yalçın, 2008). Bölgenin heyelan duyarlıı̆ğ, jeolojik birimlerin heyelan üretme potansiyellerine göre mekansal dağılımını ve derecelendirilmesini kapsar (Fell ve ark., 2008). Heyelanların geçmişte oluştukları koşullarla aynı koşullarda oluşacağı düşünülürse, gelecekteki heyelanların coğrafi konumunu tahmin etmek için heyelan duyarlılık haritalarına intiyaç vardır (Guzzetti ve ark., 1999). Heyelan duyarlılığı, tehlikelerin ve risk araştırmasının önemli bir parçası olup ve bir bölgenin doğal veya yapay tehlikelere karşı hassasiyetini ifade eder. (Kumpulainen,i 2006).

Heyelan duyarlılık haritalarının kapsamını da içeren ve ülkemizde Afet ve Acil Durum Yönetimi Başkanlığı tarafından yapılan bütünleşik afet tehlike haritaları uluslararası litaratürde "multihazard mapping" başlığı altında tüm dünyada kullanılmaktadır. Bütünleşik afet tehlike veya risk haritaları ile ilgili dünyada çok sayıda araştırma bulunmaktadır (Guzzetti ve ark., 1999; Udone ve Sah, 2002; Kumpulainen, 2006; Yalçın, 2008; Fell ve ark., 2008; Nurlu 2015; Zhongqiang ve ark., 2015).

Heyelan oluşumu, şev açısı, litoloji, yapısal özellikler, zemin türü, arazi kullanımı gibi hazırlayıcı özellikler ile deprem, yağış ve insan etkisi gibi tetikleyici pek çok faktörle ilişkilidir. Bu parametrelerin tüm yönlerini heyelan duyarlılık değerlendirmesine dahil etmek her zaman mümkün olmamakla birlikte literatürde hangi paramet- relerin bu tür değerlendirmelerde kullanıldığına dair bir standart bulunmamaktadır (Moreiras, 2005).

Heyelan duyarlıık haritasının üretilmesinde Analitik Hiyerarşi Yöntemi (AHP) ve Ağırlıklı Doğrusal Birleştirme Yöntemi (ADBY) gibi çok kriterli karar analizi tekniklerinin birlikte kullanıldığı çalışmalar, bulunmaktadır. Bu çalışmalara örnek olarak Kavzoğlu ve ark., (2012), yaptığı çalışmada, kriter ağırlıkları önemlilik derecelerine göre sırasıyla litoloji, eğim, arazi örtüsü, bakı ve yükseklik faktörlerini heyelan duyarlılık haritası oluşturulurken kullanılmıştır. Elde edilen heyelan duyarlılık haritası ile envanter haritası karşılaştırılarak CBS tabanlı çok kriterli karar analiz yönteminin, risk haritaları üretiminde etkin bir yöntem olarak kullanılabileceğini belirlenmiştir.

Heyelan duyarlııık haritalarının oluşturulması için literatürde bulanık mantık (Kanungo ve ark., 2009; Pradhan, 2010), AHP (Komac, 2006; Moradi ve ark., 2012); (Kayastha ve ark., 2013), lojistik regresyon (Lee ve ark., 2007; Pradhan ve Lee, 2010) gibi çeşitli yöntemler kullanılmıştır. Heyelan duyarlııı haritalarının oluşturulmasında frekans yöntemi sıklıkla kullanılmaktadır. Bu yöntemde dikkate alınacak parametreler CBS platformuna aktarıldıktan sonra, heyelan envanter haritası ile ilişkilendirilerek, yoğunluk analizleri yapılmaktadır (AFAD, 2015).

Isparta-Burdur arasındaki ulaşımı yarı yarıya kısaltan dağ yolu, topoğrafik yapısı, iklim koşulları ve litolojik özellikleri nedenleri ile duraylılık sorunları yaşanmaktadır. 2010 yılının Ocak ayında asfaltlanıp düzenlenerek trafiğe açılmasının ardından, çok kısa bir süre içerisinde yolda deformasyonlar meydana gelmiş, özellikle Burdur il sınırına yakın olan bölgelerde ulaşım, yer yer tek şeritten sağlanmıştır. Bu çalışmadaki temel amaç heyelan potansiyeline sahip alanların belirlenerek karar verici otoriteler açısından farkındalık oluşturmasıdır.

\section{MATERYAL VE YÖNTEM}

\section{Çalışma Alanı}

Çalışma alanı, M24b3 ve M24b4 paftaları içerisinde yer alan, Burdur Gölü' nün güneybatısında; Isparta-Burdur illeri arasındaki $4181900-4183300 \mathrm{~K}$ ve $264400-270700$ D (WGS84-S36) koordinatları arasında Burdur il sınırlar içerisinde kalan kısmını oluşturur (Şekil 1). 


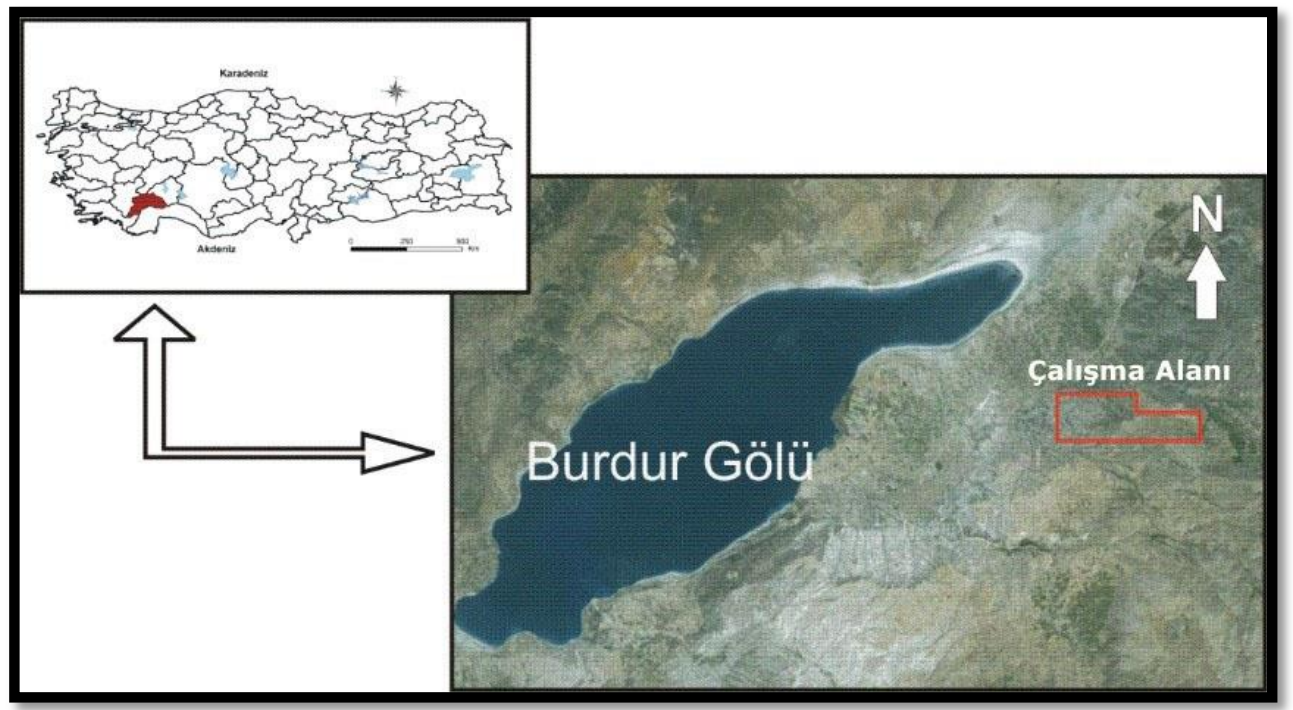

Şekil 1. Çalışma alanı yer bulduru haritası

Kara ikliminin egemen olduğu Burdur 'lli' nde yüksek dağlar, bölgeyi Akdeniz ikliminden ayırır. Yazların sıcak, kışları çok soğuk geçtiği bölgede, sıcaklıklar $14,0^{\circ} \mathrm{C}$ ile $+16,8^{\circ} \mathrm{C}$ arasında değişmekte olup, yıllık ortalama sıcaklık $2,6^{\circ} \mathrm{C}$ ' dir. Uzun yıllar aylık toplam ortalama yağış ise 54 mm'dir (MGM, 2018). Heyelanın olduğu litolojinin suyla doygun hale gelmesi heyelan duyarlılığını artırmaktadır. Özellikle yüzey eğiminin arttığı alanlardaki şiddetli yağışlar heyelanları tetiklemekte kütlenin dengesini bozarak heyelana sebep olmaktadır (Reis ve ark. 2008).

Heyelana neden olan faktörlerin belirlenmesi ve bu faktörlerin özelliklerinin ortaya konması olarak tanımlanan (AFAD, 2015) heyelan envanteri, heyelan duyarlılık haritalarını hazırlarken heyelanın yerini ve alanını doğru olarak belirlemek için çok önemlidir (Pachauri ve
Pant, 1992). Heyelanları tanımlamak için hava fotoğrafları, tarihi heyelan kayıtları,saha gözlemleri ve literatür taraması kullanılan farklı yöntemlerdir. Burdur İli çalışma alanı sınırları içerisinde herhangi bir heyelan veri kaydına rastlanmamış, heyelan lokasyonları yapılan arazi çalışmaları ile tespit edilerek, 1/25000 ölçekli topografik haritalara işlenmiştir (Şekil: 2).

\section{CBS Tabanlı Heyelan Duyarlılık Analizi}

CBS tabanlı heyelan duyarlılık haritaları oluşturulurken, uygun parametrelerin seçimi üretilecek haritaların doğruluğu ve güvenilirliğini doğrudan etkileyecektir. Duyarlılık haritalarının hazırlanması için yapılan bu çalışmada; heyelan envanteri, topografik yükseklik, jeoloji, yola yakınlık, eğim, bakı ve eğim parametreleri ArcGIS 10.0 yazııımı kullanılarak üretilmiştir.

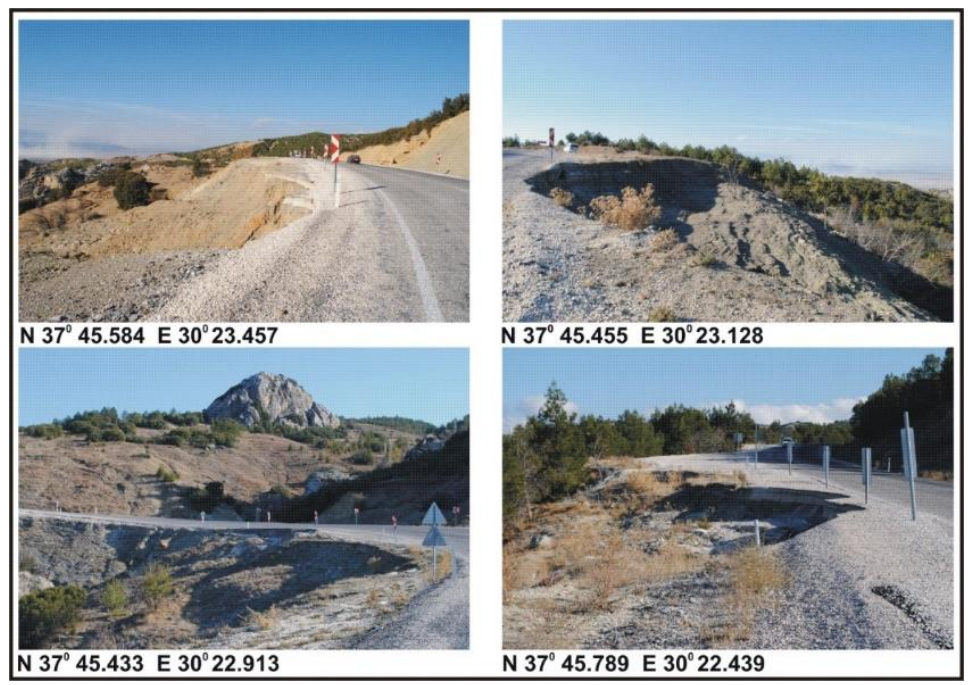

Şekil 2. Isparta-Burdur dağ yolunda meydana gelen heyelanlar 
Duyarlılık haritasının ölçeğini belirlemedeki en önemli faktör, duyarlııı haritasının amacı ve çalışma bölgesi alanıdır. Araştırılacak bölgenin alanına göre duyarlılık haritası ölçeği 1: 25000 ila 1: 100000 arasında değişebilmektedir. Bu çalışmada ise çıktı haritası ölçeği 1: 25000 olarak alınmıştır.

Her heyelan duyarlılık değerlendirme yönteminin kendine göre avantaj ve dezavantajları bulunmaktadır. Bu çalışmada, seçilen bölgede heyelan duyarlılığını değerlendirmek için Frekans yöntemi kullanılmıştır.

Lee ve Talib (2005), tarafından önerilen Frekans Oranı yönteminde, dikkate alınan parametreler CBS' ne aktarıldıktan sonra heyelan envanter haritası ile ilişkilendirilmektedir. Bu yöntemin temelini ise denklem 1'de verilen frekans oranı (FR), a ve b katsayılarının birbirlerine oranı oluşturmaktadır.

$\mathrm{FR}=\mathrm{a} / \mathrm{b}$

$\mathrm{FR}=$ Frekans oranı

$a=$ parametre alt grubundaki heyelanlı piksel sayısının toplam heyelanlı piksel sayısına oranı $b=$ parametre alt grubunun piksel sayısının, alandaki toplam piksel sayısına oranı

\section{Heyelan Duyarlılık Haritalamasını Etkileyen Para- metreler}

\section{Yükseklik}

Yüksekliğin, farklı aralıklarda heyelan duyarlılığına etki ettiği bilinmektedir (Dai ve Lee, 2002). Çalışma alanı içerisindeki 1/25000 ölçekli M24b3 ve M24b4 topoğrafik haritaları sayısallaştııılarak, 1 piksel hücre büyüklüğüne sahip sayısal yükseklik modeli (SYM) elde edilmiştir. Çalışma alanına ait, 900-1350 metre aralıklarında yükseklik haritası, değerlendirme amaçlı 5 eşit aralığa bölünerek sınıflandırılmıştır (Şekil 3a). Sahadan elde edilen heyelan envanter haritasına göre, bölgede en çok 1100-1200 metre yüksekliğindeki alanlarda heyelan oluşumuna rastlanmıştır (Tablo 1). Elde edilen SYM haritası, daha sonra diğer parametrelerin elde edilmesinde kullanılmıştır.

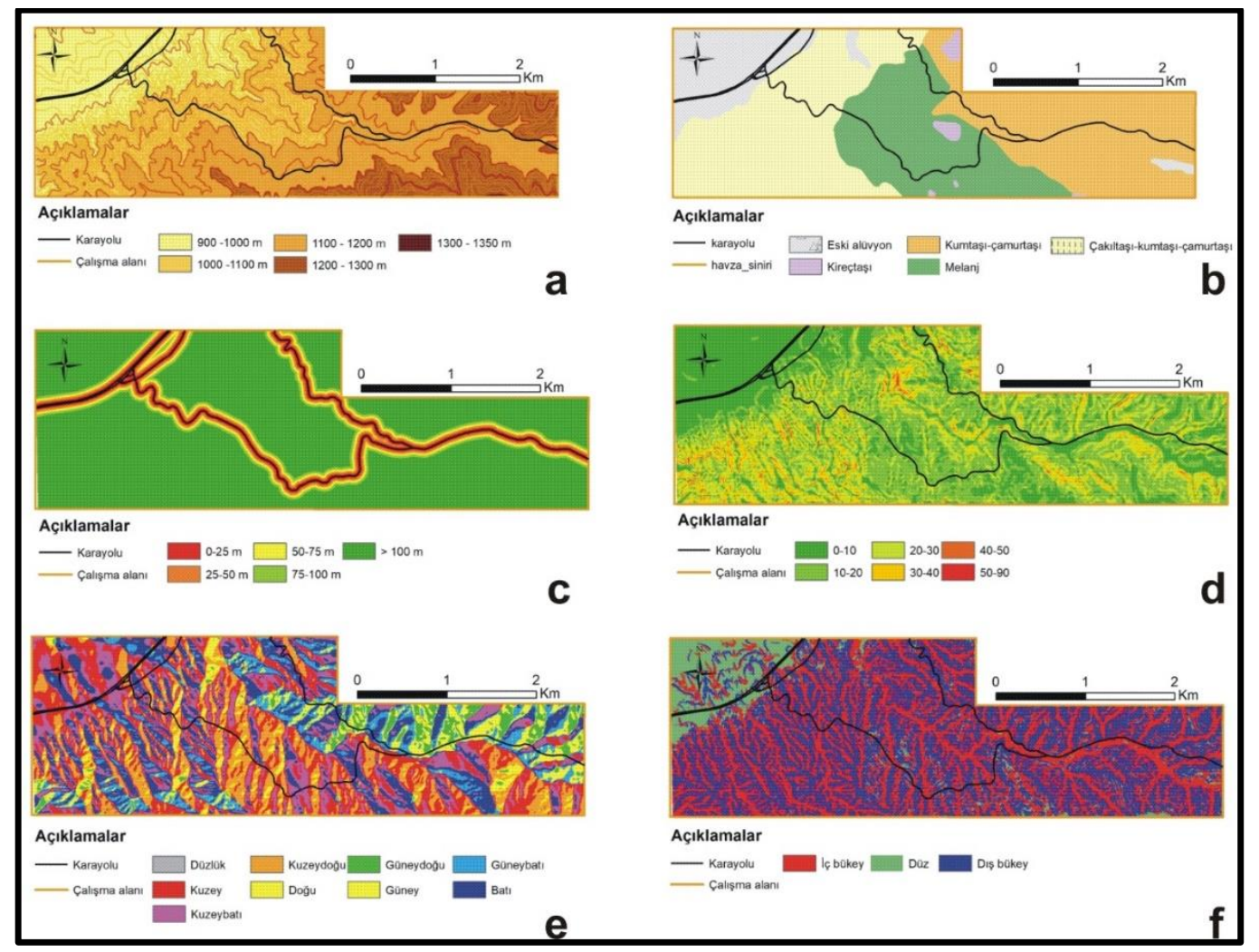

Şekil 3. Çalışmada kullanılan parametre haritaları; (a) topografik yükseklik, (b) jeoloji, (c) yola yakınlık, (d) eğim, (e) bakı, (f) eğim şekli 


\section{Jeoloji}

Bir arazinin jeomorfolojisi ile ilgili tüm detaylar, o arazinin jeolojik özellikleri belirlemektedir (Dai ve ark., 2001). Dayanım, geçirimlilik ve sertlik gibi birçok jeolojik özellik, yamaç duraylıı̆ı̆ını doğrudan etkiler (AFAD, 2015; Baeza ve Corominas, 2001). Fay, kıvrım gibi yapısal ve tektonik özellikler kayaçlarda parçalanmaya neden olarak, litolojik birimleri zayıflatacağından, yamaç duraylıı̆ı üzerinde doğrudan etkilidir.

Çalışma alanı içerisindeki birimler çakıltaşı, kumtaşı, çamurtaşı, melanj, kireçtaşı ve eski alüvyon birimlerinden oluşmaktadır. Yapılan arazi gözlemlerinde, mevcut heyelanların çakıltaşı, kumtaşı, çamurtaşı ve melanj birimlerinde geliştiği görülmüştür (Şekil 3b).

Tablo 1. Çalışma alanında kullanılan parametrelere ait frekans oranları

\begin{tabular}{|c|c|c|c|c|c|c|}
\hline PARAMETRE & \multirow{2}{*}{$\begin{array}{c}\text { Çalışma alanındaki } \\
\text { parametre altgrubuna ait } \\
\text { piksel sayısı }\end{array}$} & \multirow{2}{*}{$\begin{array}{c}\text { Çalışma alanın- } \\
\text { daki parametre } \\
\text { altgrubuna ait } \\
\text { heyelanlı piksel } \\
\text { payısı }\end{array}$} & \multirow{2}{*}{ a } & \multirow{2}{*}{ b } & \multirow{2}{*}{ FR } & \multirow{2}{*}{ NFR } \\
\hline SYM (m) & & & & & & \\
\hline $900-1000$ & 2622408 & 1096 & 0,01 & 0,26 & 0,04 & 2 \\
\hline $1000-1100$ & 2482926 & 42849 & 0,47 & 0,24 & 1,96 & 100 \\
\hline $1100-1200$ & 3388152 & 46793 & 0,52 & 0,33 & 1,58 & 81 \\
\hline $1200-1300$ & 1738407 & 0 & 0 & 0,17 & 0 & 0 \\
\hline $1300-1400$ & 7450 & 0 & 0 & 0 & 0 & 0 \\
\hline JEOLOJi & Piksel Sayısı & $\begin{array}{c}\text { Heyelanlı Piksel } \\
\text { Sayısı }\end{array}$ & a & b & FR & NFR \\
\hline Eski alüvyon & 1411437 & 0 & 0 & 0,14 & 0 & 0 \\
\hline Kireçtaşı & 131317 & 0 & 0 & 0,01 & 0 & 0 \\
\hline Kumtaşı-Çamurtaşı & 3008125 & 0 & 0 & 0,29 & 0 & 0 \\
\hline Melanj & 2440978 & 48832 & 0,54 & 0,24 & 2,25 & 100 \\
\hline Çakıltaşı-çamurtaşı-kumtaşı & 3238974 & 41912 & 0,46 & 0,32 & 1,44 & 64 \\
\hline YOLA YAKINLIK (m) & Piksel Sayısı & $\begin{array}{c}\text { Heyelanlı Piksel } \\
\text { Sayısı }\end{array}$ & a & b & FR & NFR \\
\hline 25 & 624683 & 29389 & 0,32 & 0,06 & 5,33 & 100 \\
\hline 50 & 563978 & 27505 & 0,3 & 0,06 & 5 & 94 \\
\hline 75 & 533682 & 20144 & 0,22 & 0,05 & 4,4 & 83 \\
\hline 100 & 491138 & 11061 & 0,12 & 0,05 & 2,4 & 45 \\
\hline$>100$ & 8017350 & 2591 & 0,04 & 0,78 & 0,05 & 1 \\
\hline EĞìM (derece) & Piksel Sayısı & $\begin{array}{c}\text { Heyelanlı Piksel } \\
\text { Sayısı }\end{array}$ & a & b & $\mathbf{F R}$ & NFR \\
\hline $0-10$ & 2965256 & 11331 & 0,12 & 0,29 & 0,41 & 28 \\
\hline $10-20$ & 3996081 & 53009 & 0,58 & 0,39 & 1,49 & 100 \\
\hline $20-30$ & 2299667 & 22501 & 0,25 & 0,22 & 1,11 & 75 \\
\hline $30-40$ & 809197 & 3598 & 0,04 & 0,08 & 0,51 & 34 \\
\hline $40-50$ & 155995 & 299 & 0,01 & 0,02 & 0,66 & 44 \\
\hline $50-90$ & 13147 & 0 & 0 & 0,00 & 0,00 & 0 \\
\hline BAKI & Piksel Sayısı & $\begin{array}{c}\text { Heyelanlı Piksel } \\
\text { Sayısı }\end{array}$ & a & b & FR & NFR \\
\hline North $(0-22,5)$ & 1123151 & 12280 & 0,14 & 0,11 & 1,23 & 79 \\
\hline Northeast $(22,5-67,5)$ & 1770266 & 24484 & 0,27 & 0,17 & 1,56 & 100 \\
\hline East (67.5-112.5) & 533161 & 5586 & 0,06 & 0,05 & 1,18 & 76 \\
\hline Southeast $(112.5-157,5)$ & 356379 & 0 & 0,00 & 0,03 & 0,00 & 0 \\
\hline South $(157,5-202,5)$ & 678725 & 0 & 0,00 & 0,07 & 0,00 & 0 \\
\hline Southwest $(202,5-247,5)$ & 1001243 & 2262 & 0,02 & 0,10 & 0,25 & 16 \\
\hline West $(247,5-292,5)$ & 1871433 & 18299 & 0,20 & 0,18 & 1,10 & 71 \\
\hline Northwest $(292,5-337,5)$ & 1896609 & 18924 & 0,21 & 0,19 & 1,13 & 72 \\
\hline North $(337,5-360)$ & 1008375 & 8903 & 0,10 & 0,10 & 1,00 & 64 \\
\hline EĞiM ŞEKLİ & Piksel Sayısı & $\begin{array}{c}\text { Heyelanlı Piksel } \\
\text { Sayısı }\end{array}$ & a & b & FR & NFR \\
\hline$(<-0,2)$ & 4115433 & 51160 & 0,56 & 0,40 & 1,40 & 100 \\
\hline$(-0,2-0,2)$ & 1856355 & 8344 & 0,09 & 0,18 & 0,51 & 36 \\
\hline$(>0,2)$ & 4267555 & 31234 & 0,34 & 0,42 & 0,83 & 59 \\
\hline
\end{tabular}




\section{Yola Yakınlık}

Yola yakınlık parametresi, özellikle yol çalışmaları için açılan yarmalarda, yamacın topuk bölgesindeki yük dengesini bozarak, malzemenin eğim yönünde kayma potansiyelini arttırır. Yol güzergahının belirlenmesi sırasında litolojik birimlerin suya olan hassasiyeti, yamaç ve şev eğimlerinin gözardı edilmemesi gerekmektedir. Aksi takdirde bu unsurlar bölgedeki heyelanların ana sebepleri olarak karşımıza çıkabilmektedir (Şekil 2).

Yolun yamaç duraylılığına olan etkisini belirlemek için 25 metre aralıklarla tampon bölgeler oluşturulmuş ve heyelan envanter haritasına göre heyelan alanları ve yüzde dağılımları belirlenmiştir (Şekil 3c). Bu bölgede gerçekleşen heyelanların en çok, yol yarmalarının olduğu 0-25 metre aralığındaki mesafelerde olduğu tespit edilmiştir (Tablo 1).

\section{Eğim}

Yamaç eğimi, 2000-2010 yılları arasında yapılan ve bilimsel dergilerde yayımlanmış 114 adet heyelan duyarlılık analizleri bilimsel çalışmalarının 109 tanesinde kullanılan en önemli parametredir (AFAD, 2015; Hasekioğulları ve Ercanoğlu, 2012). Heyelan duyarlılık haritasını hazırlamak için eğim haritası, sayısal yükseklik modeli kullanılarak üretilmiş ve altı eğim kategorisine ayrılmıştır (Şekil 3d). Heyelan envanter haritasına göre, heyelanların çoğu 10-20 derece eğim aralıklarında meydana gelmiştir.

\section{Bakı}

Arazi örtüsü gelişimi, toprağın nemliliği, rüzgar etkisi, günlenme gibi faktörlere etki eden bakı, toprağın dayanımı ve heyelan duyarlılığı açısından önemli bir parametredir (Dai ve Lee,2001). Sayısal yükseklik modelinden üretilen bakı haritası -1-360 derece aralığında 9 sınıfı kapsayacak şekilde üretilmiştir. En yüksek heyelan görülme olasılığı KD-KB ve $B$ yönlerinde görülmektedir (Tablo 1). Bu durum ise kuzey ve batı yönlü yamaçların nemliliğinin nispeten daha yüksek olduğundan kaynaklanmaktadır (Özşahin, 2015) (Şekil 3e).

\section{Yüzey Şekli}

Yamaçta, malzeme akışının hızlanmasını veya yavaşlamasını kontrol eden önemli bir parametredir. SYM' den elde edilen eğim analizinde, pozitif değerler dışbükey, negatif değerler içbükey ve sıfıra yakın olan değerler ise düz yamaç şeklini göstermektedir. (Şekil 3f). Frekans oranına göre bölgede, içbükey ve dış bükey yamaçlarda gelişen heyelan oranlarının birbirine çok yakın olduğu görülmüştür (Tablo 1).

\section{BULGULAR VE TARTIŞMA}

Heyelan envanter haritasındaki tüm heyelanların \%20' si sınama verisi olarak analiz sonrası için ayrılmış, diğer heyelan alanları ise model olarak kullanılmıştır. Çalışma alanınındaki heyelanlı piksel sayıları, heyelan envanter haritasında işlenen vektör formatlı poligonların raster formatına dönüştürülmesi ile hesaplanmıştır. Heyelanlı alanlardaki parametre alt gruplarının piksel sayılarını bulmak için ise, model olarak ayrılan heyelan alanlarına mask işlemi uygulanmış yani heyelanlı alanlara karşılık gelen değerler belirlenerek frekans değerleri (FR) hesaplanmıştır. FR değerlerinin normalleştirilmesi için ise, parametre alt grubundaki tüm FR değerleri, en büyük $F R$ değerine bölünüp 100 ile çarpılmış ve NFR (normalleştirilme yapılmış frekans oranları) sütunundaki değerler elde edilmiştir (Tablo 1). NFR değerlerinin büyük olması, o parametre alt grubundaki heyelan duyarlıı̆̆ınında o kadar yüksek olduğunu göstermektedir.

Elde edilen NFR değerleri, parametre haritalarına yeniden sınıflandırma ile atanarak, tüm parametre değerleri toplanıp, 5 eşit parçaya bölünerek çalışma alanı duyarıılık haritası elde edilmiştir. (Şekil: 4).

Elde edilen duyarlılık haritasına göre, en yüksek heyelan duyarlılığının olduğu alanlar, yolun geçtiği ilk 25 ve 50 metrelik tampon bölgeler olduğu görülmüştür. Bunun nedeninin ise yol yapımı sırasında açılan şevlerin, bölgede gevşek yapılı kumtaşı, çakıltaşı ve melanj birimlerinin topuk bölgelerindeki yükü arttırması olarak yorumlanmıştır. 


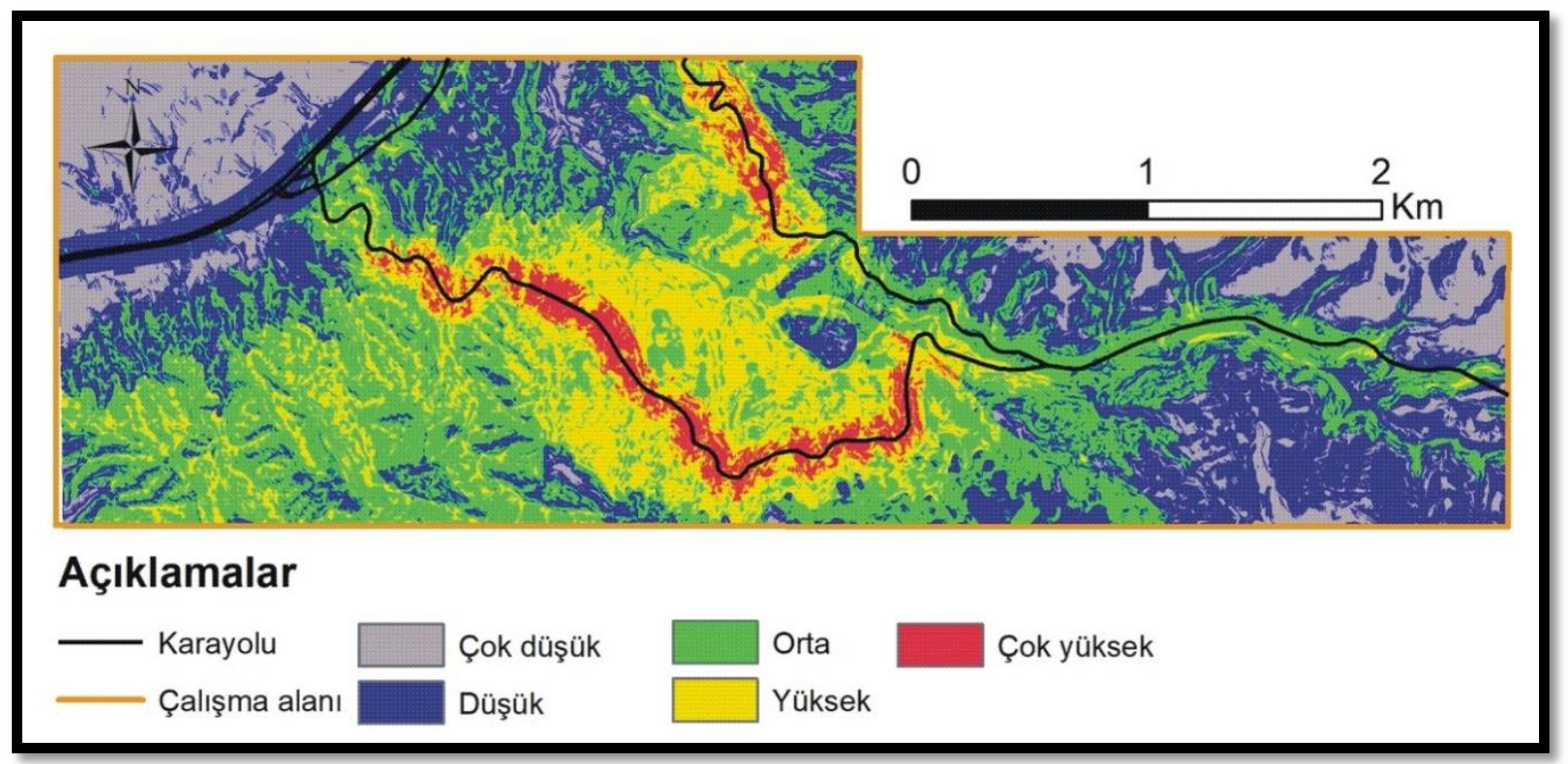

Şekil 4. Çalışma alanına ait heyelan duyarlılık haritası

Son aşamada ise ortaya çıkan heyelan duyarlılık haritasının doğruluğunu sınamak için, daha önceden ayırmış olduğumuz ve işleme dahil etmediğimiz heyelan yerlerinin, duyarlıık haritamız üzerine çıkararak, yüksek ve en yüksek alanlara düşen piksel sayıları hesap edilmiştir. En düşük ve düşük alanlarda hiç piksel çıkmazken, orta duyarlııı zonunda 625 , yüksek duyarlılık zonunda 15710 ve en yüksek duyarlılık zonunda ise 15895 piksel bulunmuştur. Elde edilen bu değerlere göre doğruluk yüzdemizi bulmak için yüksek ve en yüksek alanlara düşen piksel sayıları toplanarak; toplam heyelanlı piksel sayısına bölünerek 100 ile çarpılmiştır. $\quad \mathrm{Bu}$ işlem sonucunda: $((15710+15895) /(625+15710+15895) * 100)=\% 98$ doğruluk değerine ulaşılmıştır.

\section{SONUÇLAR}

Isparta Burdur arasındaki dağ yolunun saha gözlemleri yapılarak heyelan envanteri çıkarılmış; elde edilen bulgular CBS ortamına aktarılarak, topografik yükseklik, jeoloji, yola uzaklık, eğim, bakı ve yüzey şekli parametreleri, frekans oranı yöntemi kullanılarak heyelan duyarIılık haritalaması yapılmıştır. Bu faktörlerin seçimi, heyelan oluşumlarıyla olan ilişkilerine göre belirlenmiştir. Elde edilen sonuçlara göre çalışma alanının \%11' i çok düşük, $\% 23$ ' ü düşük, $\% 25$ ' i orta, \%14' ü yüksek ve $\% 27$ ' si çok yüksek heyelan duyarlılığı göstermiştir. Böylece ileride oluşabilecek heyelanların muhtemel gerçekleşebileceği yerler risk durumuna göre belirlenmiştir. Elde edilen duyarlılık haritasında özellikle yolun geçtiği ilk 25 ila 50 metrelik tampon bölgenin heyelana en yüksek duyarlılığa sahip alanlar olduğu ortaya konmuş, buna neden olarak ise bölgedeki zayıf tutturulmuş kumtaşı, çamurtaşı ve melanj birimlerinin, şevlerin açılması sırasındaki yamacın topuk bölgelerinde artan yük basıncına direnememesinin sebep olduğu düşünülmüştür. Çalışma alanı için üretilen heyelan duyarlııık haritasının mevcut heyelanlı alanları ne şekilde tahmin ettiğini sayısal olarak ortaya koymak için performans analizi yapılmış; \%98 oranında pikselin yüksek ve çok yüksek derecede duyarlılık içinde kaldığı görülmüştür.

$\mathrm{Bu}$ çalışmada sunulan heyelan duyarlıık haritasının karayolları, idari makamlar ve mühendisler için kaynak olabileceği, her türlü zarar azaltma çalışmaları ve strateji planlarında katkı sağlaması hedeflenmektedir. CBS tabanlı frekans yöntemi kullanılarak ve arazi gözlemleri ile desteklenen bu çalışmanın, sahadaki heyelan alanları ile tutarlı sonuç göstermesi nedeniyle benzer alanlarda kullanılabileceği anlaşılmıştır.

\section{KAYNAKLAR}

AFAD (2015). Bütünleşik Tehlike Haritalarının Hazırlanması Heyelan-Kaya Düşmesi Temel Kılavuzu. Afet ve Acil Durum Yönetimi Başkanlığı, 151 s., Ankara.

Baeza, C., Corominas, J. (2001), Assessment of shallow landslides susceptibility by means of multivariate statistical techniques. Earth Surface Processes \& Landforms 26, 251-1263.

Cruden, D.M., Varnes, D.J. (1996). Landslide Types ve Processes. Landslides Investigation ve Mitigation. Special Report 247. In: Turner, A.K. ve Schuster, R.L. (eds.), 36$75 \mathrm{pp}$.

Dai, F.C., Lee, C.F., Li, J., Xu, Z.W. (2001). Assessment of landslide susceptibility on the natural terrain of Lantau Island. Hong Kong. Environmental Geology 43 (3): 381391.

Dai, F.C., Lee, C.F. (2002). Landslide characteristics and, slope instability modeling using GIS. Lantau Island, Hong Kong, Geomorphology 42(3-4), 213-228. 
Fell, R., Corominas, J., Bonnard, CH., Cascini, C., Leroi, E., Z. Savage, W. (2008). Guidelines for landslide susceptibility hazard ve risk zoning for land use planning. Engineering Geology 102, 99-111.

Guzzetti, F., Carrara, A., Cardinali, M., Reichenbach, P. (1999). Landslide hazard evaluation: a review of current techniques ve their application in a multi-scale study. Central Italy. Geomorphology 31, 181-216.

Guzzetti, F., Reichenbach, P., Cardinali, M., Galli, M., Ardizzone, F. (2005). Probabilistic landslide hazard assessment at the basin scale. Geomorphology 72, 272-299.

Guzzetti, F., Reichenbach, P., Ardizzone, F., Cardinali, M., Galli, M. (2006). Estimating quality of landslide susceptibility models. Geomorphology 81, 166-184.

Hasekioğulları, G. D., Ercanoğlu, M. (2012). A new approach to use AHP in landslide susceptibility mapping: a case study at Yenice (Karabuk, NW Turkey). Natural Hazards 63, 1157-1179.

Kavzoglu, T., Şahin, E.K., Çölkesen, İ. (2012). Heyelan Duyarlıığının İ̉ncelenmesinde Regresyon Ağaçlarının Kullanımı: Trabzon Örneği. Harita Dergisi 147(3), 21-33.

Kanungo, D.P., Arora, M.K., Sarkar, S., Gupta, R.P. (2009). A fuzzy set based approach for integration of thematic maps for landslide susceptibility zonation. Georisk Vol. 3, Issue 1, 30-43 p.

Kayastha, P., Dhital, M.R., De Smedt F. (2013). Application of the analytical hierarchy process (AHP) for landslide susceptibility mapping: A case study from the Tinau watershed, west Nepal. Computers \& Geosciences 52, 398-408.

Komac, M. (2006). A landslide susceptibility model using the Analytical Hierarchy Process method ve multivariate statistics in perialpine Slovenia. Geomorphology 74, 17-28.

Kumpulainen, S. (2006). Vulnerability concepts in hazard anda risk assessment, Natural and Technological $\mathrm{Ha}$ zards and Risks Affecting the Spatial Development of European Regions, Special Paper 42, 65-74.

Lee, S., Talib, J.A. (2005). Probabilistic landslide susceptibility ve factor effect analysis. Environmental Geology 47: 982-990.

Lee, S., Ryu,J.-H., Kim, I.-S. (2007). Landslide susceptibility analysis ve its verification using likelihood ratio, logistic regression, ve artificial neural network models: case study of Youngin. Korea. Landslides 4, 327-338.

MGM (2018). Orman ve Su İşleri Bakanlığı, Meteoroloji Genel Müdürlüğü, Haber Bülteni, Ocak-2018, https://www.mgm.gov.tr/FILES/resmi-istatistikler/2018ocak-iklimVerileriHaberBulteni.pdf (Erişim tarihi; 15 Şubat 2018)

Moradi, M., Bazyar, M.H., Mohammadi, Z. (2012). GIS Based Landslide susceptibility mapping by AHP method, a case study, Dena City, Iran. Journal of Basic ve Applied Scientific Research 2(7), 6715-6723.

Moreiras, M. S. (2005). Landslide susceptibility zonation in the Rio Mendoza Valley, Argentina. Geomorphology 66, 345-357.

Özşahin, E. (2015). Coğrafi Bilgi Sistemleri yardımıyla heyelan duyarlıık analizi: Ganos Dağı Örneği (Tekirdağ). Harita Teknolojileri Elektronik Dergisi 7(1): 47-63.

Pachauri, A.K., Pant, M. (1992). Landslide hazard mapping based on geological attributes. Engineering Geology 32, $81-100$

Pradhan, B. (2010). Landslide Susceptibility mapping of a catchment area using frequency ratio, fuzzy logic ve multivariate logistic regression approaches. Journal of the Indian Society of Remote Sensing 38 (2) 301-320.

Pradhan, B., Lee, S. (2010). Landslide susceptibility assessment ve factor effect analysis: backpropagation artificial neural networks ve their comparison with frequency ratio ve bivariate logistic regression modelling. Environmental Modelling \& Software 25, 747-759.

Reis, S., Bayrak, T., Yalçın, A., Atasoy, M., Nişancı, R., Ekercin, S. Rize bölgesinde yağış heyelan illişkisi, Jeodesi, Jeoinformasyon ve Arazi Yönetimi Dergisi, 2, 99, 5-9.

Udono, T., Sah, A.K. (2002). Hazard mapping and vulnerability assessment, Regional Workshop on Total Disaster Risk Management, 7-9 August 2002.

Yalçın, A. (2008). GIS-based landslide susceptibility mapping using analytical hierarchy process ve bivariate statistics in Ardesen (Turkey). Catena 72, 1-12.

Liu, Z., Nadim, F., Garcia-Aristizabal, A., Mignan, A., Fleming, K., Luna, B. Q. (2015). A three-level framework for multirisk assessment. Georisk 9, 2, pp. 59-74. 